\title{
Los límites temporales de la libertad de expresión en los procesos electorales: una revisión a los casos de México, Costa Rica, Colombia y Uruguay
}

\author{
Noelia Hidalgo Rodríguez
}

https://doi.org/10.35242/RDE 20213210

Nota del Consejo Editorial

Recepción: 25 de mayo de 2021.

Revisión, corrección y aprobación: 5 de julio de 2021.

Resumen: La libertad de expresión es uno de los principales derechos de las personas en los regímenes democráticos. Como todos los demás derechos, no es absoluto. La libre expresión de las ideas, en el contexto de los procesos electorales, se manifiesta a través de la garantía de difusión de propaganda electoral; sujeta a determinadas restricciones en pro del interés social. Una de estas limitantes es aquella en razón de la temporalidad, conocida generalmente como veda electoral o tiempo de reflexión. Este artículo pretende mostrar, de forma descriptiva, los límites temporales a la publicidad electoral en América Latina, específicamente en los casos de México, Costa Rica, Colombia y Uruguay; así como también brindar una breve explicación de los términos 'libertad de expresión' y 'propaganda electoral' y su relación con la democracia y los procesos electorales.

Palabras clave: Propaganda electoral / Tregua política / Prohibición / Libertad de expresión / Derecho a la información / Derechos humanos.

Abstract: Freedom of speech is one of the main human rights in democratic regimes. As all the other rights, it is not absolute. The free expression of ideas, in the context of electoral processes, is expressed through the guarantee to widespread political advertising; subject to certain restrictions for social interest. One of these limitations is the temporality, generally known as an electoral silence. This paper descriptively, attempts to show time limits to electoral advertising in Latin America, specifically in the cases of Mexico, Costa Rica, Colombia and Uruguay; as well as an explanation for the meaning of free expression and political advertising.

Key Words: Political advertising / Political truce / Ban on freedom of speech / Right to information / Human rights.

\footnotetext{
Costarricense, abogada, correo electrónico: nohe.hidalgo@gmail.com. Licenciada en Derecho por la Universidad de Costa Rica, egresada de la Maestría Profesional en Derecho Constitucional de la Universidad Estatal a Distancia. En la actualidad, se desempeña como defensora pública.
} 


\section{DERECHO ELECTORAL}

\section{APUNTES INTRODUCTORIOS}

La Declaración Universal de los Derechos Humanos (DUDH) ${ }^{1}$ consagra en el artículo 19 la facultad que tiene toda persona de opinar y emitir ideas de manera expedita; que incluye también la potestad de investigar, recibir y difundir informaciones por cualquier medio y sin límite de fronteras. Es tal su importancia que ha sido incluido en otros instrumentos de derechos humanos como la Declaración Universal de los Derechos del Hombre y del Ciudadano en el numeral 18; el Pacto Internacional de Derechos Civiles y Políticos, artículo 12; la Convención Americana de Derechos Humanos, artículo 13 y en el numeral 10 del Convenio Europeo de Derechos Humanos, entre otros.

El fundamento de este derecho recae, a la vez, en el principio de dignidad humana desprendida del ordinal 1 de la DUDH, que entiende al ser humano como un sujeto individual y social con características particulares necesarias para realizarse a sí mismo. Roberto Andoro, citado por Tinant (2011, p. 1), alude a la premisa de que ser persona equivale a ser digno, donde la dignidad ontológica es una cualidad inseparablemente unida al ser mismo del hombre, mientras que desde la ética este concepto hace referencia al 'obrar'. En el mismo orden de ideas, Tinant (2011, p. 1), de la noción de dignidad humana, basado en el valor que debe reconocerse al hombre por el solo hecho de serlo, concluye que el ser humano es la única especie que se posee y se determina voluntariamente.

De la capacidad que tiene el individuo de determinarse a sí mismo es que nacen las libertades del pensamiento, cuya esencia descansa en la potestad de adoptar ideas o creencias, y a no ser perturbado por causa de las posturas que se adopten en el ejercicio pleno de ese derecho; de modo tal que cuando el libre pensamiento es enunciado, se configura la libertad de expresión. Según la esfera en la que se exterioricen tales pensamientos así será el nombre por adoptar, a saber: libertad de culto en el área religiosa, la libertad de cátedra en la educación, libertad científica y de creación en la ciencia y el arte, libertad intelectual cuando lo tutelado es la propiedad intelectual y la libertad de expresión en el sentido de las comunicaciones públicas.

De ahí se extrae que las manifestaciones de la libertad ideológica y de pensamiento están vinculadas entre sí, por cuanto todas nacen de la autodeterminación del individuo. Sobre esta misma línea, pero sumando,

1 DUDH, en lo sucesivo. 


\section{DERECHO ELECTORAL}

además, el derecho a la información como medio para la existencia de estos extremos, apunta Peralta lo siguiente: "Entonces, la libertad ideológica, para existir verdaderamente, requiere del conocimiento, de la información, exige tanto el derecho a la información y a la educación como la libertad de expresión e información y la libertad de enseñanza" (2012, p. 253).

Tanto la libertad de conciencia como los derechos que de ella se desprenden forman parte del catálogo de derechos humanos de primera generación, destinados a la protección del ser humano en su individualidad contra cualquier agresión de algún órgano público nacional o foráneo, al haber sido adoptados en las distintas cartas de garantías del derecho internacional. Estos derechos, que han sido positivizados en las constituciones de los países objeto de este estudio, a saber, México, Costa Rica, Colombia y Uruguay, no solo fungen como un tope al poder de los Estados, sino que también encuentran restricciones en los distintos ordenamientos jurídicos. Lo anterior revela que los derechos humanos no son, de ningún modo, absolutos y, por tanto, están sujetos a límites que responden a las exigencias propias de la vida en sociedad (Tórtora, 2010, párr. 2).

A continuación, se repasará el concepto de 'libertad de expresión' y su necesaria unión con el derecho a la información, los límites generales y su relación con los comicios electorales. Posteriormente, se abordarán los casos de México, Costa Rica, Colombia y Uruguay en cuanto a las barreras de la libertad de expresión en los comicios, específicamente en lo concerniente a la difusión de propaganda electoral. A modo de corolario se realizará una comparación general entre los casos expuestos.

\section{LIBERTAD DE EXPRESIÓN COMO CONCEPTO}

La Relatoría Especial para la Libertad de Expresión (2019, p. 15), refiriéndose al sistema interamericano de derechos humanos, indicó que la libre expresión se caracteriza por ser un derecho con dos aristas: una individual, cuando la persona expresa sus pensamientos, ideas e informaciones; y una dimensión colectiva, en lo referente al derecho de la sociedad de procurar y recibir información. Esto último adquiere especial sentido cuando se retoma quepara el pleno disfrute de la potestad de expresar ideas se requiere poder buscar información, recibirla y posteriormente decidir si se difunde o no. (Peralta, 2012). 


\section{DERECHO ELECTORAL}

La Convención Americana de Derechos Humanos plasma en el numeral 12 inciso 1) esa doble cara de la libertad expresión: emitir opiniones y recibir informaciones, cuando establece que:

Toda persona tiene derecho a la libertad de pensamiento y de expresión. Este derecho comprende la libertad de buscar, recibir y difundir informaciones e ideas de toda índole, sin consideración de fronteras, ya sea oralmente, por escrito o en forma impresa o artística, o por cualquier otro procedimiento de su elección.

La libertad de expresión, como base para la formación de opinión, requiere del acceso a la información, con lo que convierte a ambos en conceptos, si bien autónomos, concatenados el uno del otro en tanto las personas, para tomar conciencia sobre los diversos temas que componen la vida en sociedad y de este modo expresar sus concepciones, necesitan de información no solo de acceso público, sino también de aquella que terceros manifiestan públicamente.

La libertad de expresión es un derecho imprescindible de la democracia que permite al ciudadano desarrollar opiniones críticas sobre temas que merezcan su atención. Resulta inconcebible que los individuos puedan autodeterminarse a plenitud en una sociedad en la cual las personas no puedan manifestar sin tapujos sus creencias y opiniones públicamente, sin censura previa, pero con el apercibimiento de la responsabilidad que ello carga. Al efecto, esta garantía debe estar íntimamente ligada con el derecho a la información. No es posible ejercer de forma plena la libertad de conciencia sin acceso a información, a tal punto que incluso se equiparan como conceptos al depender uno del otro y viceversa. Resulta, entonces, que para la formación de opinión, la libertad de expresión se manifiesta como piedra angular. Bajo esta idea manifestó Peralta:

En consecuencia con semejante doctrina podemos subrayar que sin una comunicación libre no puede existir una sociedad libre ni hacerse realidad, por tanto, el dogma de la soberanía popular, de ahí que este derecho a una comunicación libre adquiera el carácter de una libertad con verdadero alcance institucional. Estamos, pues, ante algo más que un derecho de libertad al admitir esa consideración relativa a la libertad de expresión que la convierte en una verdadera garantía institucional del sistema democrático. (2012, p. 266). 


\section{DERECHO ELECTORAL}

Desde la faceta de los individuos como gobernados, la conjunción de ambos derechos orienta a exigir y acceder a información de carácter público a las instancias, y a raíz de esto no solo tomar conciencia, sino también manifestar su descontento o, por el contrario, su apoyo a las políticas adoptadas por los poderes del Estado.

Ahora bien, resulta elemental tener claro qué implica la libertad de expresión, a la luz de lo estipulado por la Convención Americana de Derechos Humanos, la Declaración Universal de Derechos Humanos y el Pacto Internacional de Derecho Civiles y Políticos. Para empezar, el Preámbulo de Principios sobre Libertad de Expresión (2000, párr. 9) considera la importancia de esta garantía para el goce de los demás derechos humanos consagrados en la Convención, y que esta no constituye una mera concesión para los Estados, sino un derecho fundamental autónomo (párr. 12).

Asimismo, con arreglo de los principios de este documento, cabe definir la libre comunicación como fundamental, inalienable y autónoma, que contempla el derecho a la búsqueda, recibo y difusión de información y opiniones, en todas las formas de manifestación posibles; en igualdad de condiciones y sin sufrir, por su causa, discriminación alguna por razones de género, raza, sexualidad, preferencias religiosas o políticas, estatus social, idioma, lugar de nacimiento o cualquier otra condición social. Debe sumarse el derecho a información pública y a su cuestionamiento y, por último, la potestad de comunicar opiniones por cualquier medio y forma sin censura previa.

La Declaración Universal de los Derechos Humanos apunta en el ordinal 19 que nadie debe ser molestado ni perseguido por manifestar sus opiniones tanto en público como en privado De este instrumento resulta interesante que, antecediendo a la libertad de expresión, se enuncian las libertades de pensamiento en el artículo $17 \mathrm{y}$, posteriormente, en el numeral 18, se contemplan las distintas formas en las que la libre manifestación de las ideas es mostrada, según sea su esfera de aplicación. Es decir, se contempla no solo la capacidad de opinar abiertamente, sino, además, la libertad religiosa y de cátedra.

Por otro lado, el Pacto Internacional de Derechos Civiles y Políticos, en el artículo 19, expone en tres incisos la prohibición de censurar a las personas a causa de sus opiniones, pero deja claro que el ejercicio de este derecho no es ilimitado, sino que está sujeto a restricciones, las cuales deben cumplir con tres requisitos esenciales para su validez: 1. Previstas 


\section{DERECHO EIECTORAL}

por ley, 2. Necesarias para asegurar el respeto a los derechos y a la reputación de las demás personas y 3. Necesarias para proteger la seguridad nacional, el orden público, la salud o la moral públicas.

De la suma de las definiciones de estos instrumentos internacionales, y como oportunamente lo apunta Peralta (2012), puede decirse que la libertad de expresión es el derecho que le permite al ser humano emitir, públicamente $\mathrm{o}$ en privado, juicios, creencias, pensamientos y opiniones de carácter personal y subjetivo; sin temor a ser censurado o perseguido a causa de ello. Tal cual se establece en el Pacto Internacional de Derechos Civiles y Políticos, la libre expresión de las ideas no responde a un ejercicio ilimitado, sino que encontrará, variando en cada ordenamiento jurídico, restricciones sometidas al principio de legalidad, y únicamente basadas en la necesidad de respetar los derechos de terceros y su reputación, así como el orden, la moral, la salud y la seguridad públicas.

Para finalizar esta conceptualización de la libre expresión y considerando las normas recién citadas, viene a bien mencionar dos categorías dentro de las cuales pueden agruparse las restricciones generales mencionadas: 1. Las que tutelan el honor de los individuos. Esto es contra las afirmaciones opuestas a derecho, que agreden la dignidad ajena las cuales son arbitrarias, difamatorias, insultantes, injustificadas e inverificadas, sumado al respeto por la intimidad, como el luto y el dolor ajeno (Lozano, 2000); y 2. Las destinadas a tutelar el bien público. Esta idea es bien explicada por Lozano al mencionar lo siguiente:

La libertad de expresión se escribe con letras mayúsculas, claro. Es fundamental. Es indispensable. Es imprescindible. Debería ser intocable. Debería ser invulnerable. Pero su aplicación y sus expresiones cotidianas no se pueden sustraer del respeto y guarda de otros derechos y libertades.

Tal como lo hemos visto ya, en términos generales se han acepado dos grandes bloques de límites jurídicos a la libertad de expresión. El primero, referido a la intimidad, la honra, la dignidad, la reputación y el buen nombre de los demás. El segundo, referido al bien público, preferentemente expresado en terrenos de seguridad, salud, moral pública u orden público, como veremos en lo que sigue. (2000, p. 249). 


\section{DERECHO ELECTORAL}

Lozano apunta que la libertad de expresión no ha nacido con el fin de crearle un buen nombre a ninguna persona (2000); sin embargo, sí debe tenerse presente que ninguno de los derechos posee carácter de absoluto y que en virtud de esta cuestión resulta imperativo guardar respeto por el ámbito de intimidad de los demás individuos. Como bien se dejó constando en las cartas de derechos humanos mencionadas en el presente apartado, la libertad de expresión debe ser tal sin censura previa, pero ello conlleva, a su vez, una responsabilidad por parte de quien emite su juicio. Esta responsabilidad tiene que ver coincidentemente con la idea de no divulgar información difamatoria o calumniosa, aunado al respeto por el interés general. Justo en este aspecto es que se habla del orden, la moral, la salud y la seguridad públicas como el lindero de la libre difusión de la opinión.

\section{LA LIBERTAD DE EXPRESIÓN Y SU RELACIÓN CON LA DEMOCRACIA Y LOS PROCESOS ELECTORALES}

Como se ha venido desarrollando, la libertad de expresión representa un derecho humano autónomo $y$, también, funge como garantía para todas las demás formas de libertad que se consagran. Ergo, es un derecho en sí mismo y a la vez representa una condición sine qua non para el goce de otros derechos. Dos caras de una misma moneda son las que la permiten: una individual, que asegura a las personas espacios esenciales para desplegar su autonomía, autoexpresión y autorrealización individual; y una social o política, indispensable para el correcto funcionamiento de la democracia y del autogobierno (Morán y Valencia, 2016).

Respecto a este último punto, al que nos enfocaremos en este momento, Alexander Meiklejohn, citado por Fiss (s.f., p. 52), comprendía la libertad de expresión como funcional al concepto de democracia (que a su vez entendía como el autogobierno de la ciudadanía) para mantener la vitalidad del debate público, pero además en el sentido de que el buen desenvolvimiento de la democracia requiere de ciudadanos informados que puedan evaluar la labor del gobierno. Por ello, Meiklejohn ligaba la libertad de expresión con la mejora de la percepción del sistema político de las necesidades e intereses de los ciudadanos.

A raíz de este ligamen, el autor, citado por Marciani (2005), observaba un vínculo directo entre la libertad personal y la política, a través de la manifestación de las ideas de los individuos; de modo que para que el electorado estuviese debidamente informado no debía imponerse 


\section{DERECHO EIECTORAL}

restricciones al libre flujo de la información. Continuaba apuntando que la democracia perdía su esencia si quienes ostentaban el poder manipulaban a los electores, reteniendo información e impidiéndoles formular críticas. Así las cosas, este teórico consideraba que si el elector estaba frente a la capacidad de formarse una opinión propia, ello incidiría necesariamente a la hora de ejercer el voto, el cual acabaría siendo un voto informado y mucho más consciente (citado por Marciani, 2005).

Como lo señalan Morán y Valencia, la libertad de expresión, en su dimensión social, cumple en los sistemas democráticos tres funciones esenciales que son:

- Mantener abiertos los canales para el disenso y el cambio político.

- Servir de contrapeso al ejercicio del poder, a través de la opinión pública como representación del cuestionamiento ciudadano de la labor pública.

- Formar electores conscientes e informados sobre asuntos políticos. (2016, pp. 157-158).

En síntesis, la libre expresión trabaja como garantía social al poner en marcha la democracia, en el tanto que forma votantes conscientes, dotados de herramientas para diferir la labor de los gobernantes y porque, desde los procesos electorales, no han sido coartados en su derecho de acceder a la información ofrecida por los candidatos y los partidos políticos. Esta información a la que se hace referencia es la propaganda electoral.

Anteriormente se mencionó que dentro de los límites generales a la libertad de expresión se encontraba el orden público. Uniendo las ideas desarrolladas a lo largo de estos apartados, conviene hablar de la propaganda política como manifestación de la libertad de expresión, y de las limitaciones que le son impuestas a la luz de las contiendas electorales, con el fin de preservar el orden público.

Para empezar, es pertinente acotar qué se entiende por propaganda político-electoral o proselitista, Muñoz acotó:

Dirigida a las masas, la propaganda política intenta ejercer su influjo más con efectos emocionales e inconscientes que con la persuasión o mediante la razón. La propaganda se presenta de modo exagerado, simple y superficialmente. No obstante, el 


\section{DERECHO EIECTORAL}

carácter emotivo, irracional del mensaje propagandístico, se requiere un gran equipo profesional, de especialistas, que tienen que saber interpretar encuestas y sondeos, hacer análisis sociopolíticos, estudiar la personalidad de los candidatos. (1988, p. 549)

Es viable indicar así que la propaganda proselitista es la actividad dirigida a influenciar a los votantes, con el fin de que estos tomen decisiones, adopten determinadas posturas o apoyen a los candidatos del partido político que los promueve. El Diccionario electoral (IIDH, 2017, p. 885) define este tipo de propaganda como la preparada por los partidos políticos y candidatos con el propósito de captar los votos del electorado para conseguir el mandato político.

La propaganda político-electoral es una manifestación clara de la libertad de expresión, esta garantía, unida con el derecho a la información, forma parte de los principios esenciales de este concepto. Se ejerce de distintas formas, a saber: por medio de la televisión, radio, prensa, folletos, carteles, pancartas, letreros, altavoces, mítines, caravanas, caminatas e internet y redes sociales, servicios de mensajería de texto, entre otros (IIDH, 2017, p. 886-887).

Claramente el ejercicio de la libertad de expresión en su arista política, manifestada a través de la difusión de propaganda electoral, no es, de ninguna forma, absoluto e irrestricto. Dependiendo del ordenamiento jurídico del que se trate, así serán las limitaciones que pesen en su contra. A modo de ejemplos generales, podemos mencionar como reservas las indicadas por Rivera y Abarca que son:

a) Temporales, cuando se limitan a un periodo específico.

b) Prohibición de invocar motivos religiosos.

c) Taxatividad de medios de comunicación permitidos. En el caso costarricense, el anterior Código Electoral solo permitía la difusión de propaganda político-electoral en radio, prensa y televisión, empero el Código del 2009 amplió el espectro de posibilidades, incluyendo los medios de comunicación alternativos vinculados a internet.

d) Espaciales, cuando, por ejemplo, se prohíbe la colocación de propaganda en vías públicas. (2010, p. 10). 


\section{DERECHO ELECTORAL}

Considerando que cada legislación determina los motivos por los cuales fija barreras a la propaganda electoral, nos orientaremos específicamente, a los límites temporales que han sido establecidos en cuatro países latinoamericanos: México, Costa Rica, Colombia y Uruguay. Esto, una vez que se finalizó con la conceptualización de los términos libertad de expresión' y 'propaganda electoral' y su relación con los procesos democráticos.

\section{Límites temporales a la propaganda político-electoral en AmÉrica latina: los casos de México, Costa Rica, Colombia y Uruguay}

Como bien se señaló de previo, dentro de los topes que los Estados han fijado a la difusión de propaganda electoral, como manifestación de la libre expresión, se encuentra aquel en razón del espacio temporal avalado para ello. A contrario sensu, los ordenamientos jurídicos que se mencionarán en este apartado prohíben la divulgación de propaganda partidaria en periodos de tiempo específicos.

En este apartado se identificarán las limitaciones impuestas en los casos de México, Colombia y Uruguay, en comparación con Costa Rica. La selección de estos casos obedece a que cada uno de ellos muestra las diferentes matizaciones que pueden presentar en su estructuración la administración y la justicia electoral, lo que permite abarcar la totalidad de las variaciones del modelo latinoamericano.

Por ejemplo, en cuanto al órgano que vigila el cumplimiento de las restricciones y la impugnación de sus decisiones, Uruguay (Corte Electoral) -el más parecido a Costa Rica- posee un tribunal que realiza tanto funciones jurisdiccionales como de administración electoral; mientras que en el caso colombiano, un tribunal administrativo se encarga de la justicia electoral y el Consejo Nacional Electoral, junto con la Registraduría Nacional del Estado Civil se encargan de la organización electoral. Por último, y a diferencia a la vez de estas dos variantes, México presenta un tribunal electoral especializado ${ }^{2}$ perteneciente al Poder Judicial y un organismo encargado de la administración del proceso, el Instituto Nacional Electoral (García, 2019).

\footnotetext{
2 A cargo del Tribunal Electoral del Poder Judicial de la Federación, los Tribunales Colegiados de Circuito y los Juzgados de Circuito.
} 


\section{DERECHO ELECTORAL}

También se ubican semejanzas y diferencias en la elevación a rango constitucional del derecho a la libre expresión, y en cuanto a la duración de los periodos de campaña y de veda electoral, donde incluso una de las naciones analizadas no contempla lapso de restricción previa al día de los comicios.

En lo propio a libertad de expresión, utilizándola como una suerte de índice proxy -a falta de un mejor instrumento estandarizado de medición-, la Clasificación Mundial de Libertad de Prensa 2021 muestra que la situación de cada país seleccionado presenta variaciones sustanciales, esto de acuerdo con de la Organización Reporteros Sin Fronteras, que utiliza el pluralismo y el nivel de ambiente y censura dentro de los indicadores que evalúa. La ubicación tan disímil de cada uno de estos países hace interesante la comparación, pues obliga a revisar si este tipo de restricciones (se insiste en que alguno de los casos analizados ni siquiera posee una veda temporal) impacta la valoración de esa organización sobre el respeto a la libertad de expresión. Asimismo, utilizando otro índice para intentar aproximarnos a esta cuestión, el Democracy Index (Economist Intelligence, Unit, 2021, pp. 9-10) muestra que Costa Rica y Uruguay se ubican en igualdad de condiciones en el respeto por las libertades civiles $(9,71$ puntos sobre 10 posibles), Colombia aparece en un tercer puesto $(7,94)$ y México queda rezagado al último lugar $(5,88)$.

En esa dirección cabe señalar que no parece existir una correlación entre la presencia (o ausencia) de vedas temporales y el puesto que se ocupa en la Clasificación Mundial de Libertad de Prensa o en la valoración del respeto por las libertades civiles del Democracy Index. En el caso de la Clasificación Mundial de Libertad de Prensa de 2021, Costa Rica se coloca en la posición 5 , seguida por Uruguay en el número 18 , y muy alejados ya Colombia en la posición 134 y México en el 143; mientras tanto, como se vio, el Democracy Index sitúa en plano de igualdad a Uruguay y Costa Rica, algo más atrás a Colombia y totalmente rezagado a México. Sin embargo no se corresponde propiamente en los límites a la difusión de propaganda política, puesto que como se verá luego la veda es más severa en el caso costarricense (situado en ambas mediciones como un país en el que la libertad de expresión goza de muy buena salud) que en Colombia.

Con todo, es menester diferenciar los términos de propaganda electoral o política (del cual ya se ha hecho mención ut supra, pero que se retomará 


\section{DERECHO ELECTORAL}

más adelante), según las definiciones que se establezcan en las legislaciones de los países seleccionados como objeto de estudio, con el de propaganda gubernamental.

El primero de ellos responde, y sin aras de caer en repeticiones innecesarias, al conjunto de escritos, publicaciones, imágenes, grabaciones, proyecciones y expresiones que durante la campaña electoral producen y difunden los partidos políticos, los candidatos registrados y sus simpatizantes, con el propósito de presentar ante la ciudadanía las candidaturas registradas, contender con otros partidos políticos o con otros candidatos; y a exaltar y dar publicidad a los logros del Gobierno, utilizada en campaña electoral a favor del partido político que llevó al poder al mandatario, diputados o autoridades de turno (Corona, s.f.).

Un segundo concepto es el de propaganda gubernamental, ampliamente definido por el Tribunal Electoral del Poder Judicial de la Federación, en México, como la difundida por los poderes federales, estatales y municipales sobre el conjunto de actos, escritos, publicaciones, imágenes, grabaciones, proyecciones y expresiones que llevan a cabo los servidores públicos o entidades públicas que tenga como finalidad difundir, para el conocimiento de la ciudadanía, la existencia de logros, programas, acciones, obras o medidas de Gobierno para conseguir su aceptación (SUP-RAP-119/2010, p. 269). Un ejemplo de ello sería cuando la institución encargada de velar por la seguridad social publicita la cantidad de nuevos empleos obtenidos a lo largo de esa administración.

Respecto a la propaganda electoral, dos son los momentos en los que se suscita, a saber: en la precampaña y en la campaña electoral. La primera responde a la suma de actos que realizan los partidos políticos, sus militantes y simpatizantes para elegir las candidaturas a puestos de elección popular (Capital Digital, 2017, párr. 1); y la segunda, es decir, la campaña electoral, es definida por el Diccionario electoral de la siguiente forma:

Puede definirse como campaña electoral al conjunto de actividades organizativas y comunicativas realizada por los candidatos y partidos, que tiene como propósito la captación de votos. Estas actividades están sujetas a normas y pautas de actuación que garanticen y permitan la igualdad de los competidores, la limpieza y transparencia del proceso electoral y la neutralidad de los poderes públicos. (IIDH, 2017, p. 93). 


\section{DERECHO EIECTORAL}

Una vez realizadas las consideraciones anteriores, se procederá a desarrollar el tema respecto a su regulación en México, Costa Rica, Colombia y Uruguay; y se finalizará con una comparación general entre los países mencionados.

\subsection{México}

El ordenamiento jurídico mexicano fija todo lo concerniente a la materia electoral en distintas leyes y reglamentos. Para empezar, la Constitución Política ${ }^{3}$ establece las bases, que son desarrolladas en la Ley General de Instituciones y Procedimientos Electorales del 2014 (LGIPE), Ley General del Sistema de Medios de Impugnación en Materia Electoral, Ley General de Partidos Políticos (LGPP), Reglamento de Elecciones, Reglamento de Fiscalización, entre otros. La propaganda electoral se encuentra regulada principalmente en la carta magna, Ley General de Instituciones y Procedimientos Electorales y LGPP.

La Constitución Política de los Estados Mexicanos, en el numeral 41, estipula los cimientos sobre los cuales debe legislarse en esta materia, y le otorga al Instituto Nacional Electoral (INE) la competencia de administrar los tiempos en radio y televisión a los cuales tienen derecho los partidos políticos. Al respecto Corona apunta:

El discurso en materia electoral se encuentra sujeto a la protección constitucional, pero también a las limitantes establecidas al respecto, se destaca lo establecido en el artículo 41, base III, Apartado C, párrafo primero de la Constitución, en el cual se establece que en la propaganda política o electoral que difundan los partidos deberán abstenerse de expresiones que denigren a las instituciones y a los propios partidos o que calumnien a las personas. (s.f, p. 8).

Como se desprende, si bien la libertad de difundir ideas de cualquier índole, tutelada precisamente por la libertad de expresión, es un derecho fundamental reconocido en la carta política en el artículo 6; también es cierto que en su contra pesan restricciones de distintos tipos, dentro de las cuales se encuentran las que lo son por razón de la materia electoral.

\footnotetext{
3 última reforma de 2020. Se entenderá por sus siglas como: CPEUM.
} 


\section{DERECHO EIECTORAL}

Al respecto, este órgano, por medio de la resolución n. ${ }^{\circ}$ INE/CG338/2017, en el apartado $n .^{\circ}$ IV.C, señaló lo siguiente:

La libertad de expresión y el derecho a la información son dos principios constitucionales funcionalmente centrales en un Estado constitucional y tienen una doble faceta: por un lado, aseguran a las personas espacios esenciales para el despliegue de su autonomía y, por otro, gozan de una vertiente pública, colectiva o institucional que los convierte en piezas básicas para el adecuado funcionamiento de la democracia representativa.

En ese sentido, el artículo $6.0^{\circ}$ constitucional reconoce con el carácter de derecho fundamental a la libertad de expresión e información, así como el deber del Estado de garantizarla, derecho que a la vez se consagra en los artículos 19, párrafo 2, del Pacto Internacional de Derechos Políticos y Civiles y 13, párrafo 1, de la Convención Americana sobre Derechos Humanos.

Conforme a los citados preceptos, si bien el ejercicio de dicha libertad no es absoluto, encuentra límites en cuestiones de carácter objetivo, relacionadas con determinados aspectos de seguridad nacional, orden público o salud pública, al igual que otros de carácter subjetivo o intrínseco de la persona, vinculados principalmente con la dignidad o la reputación, debe presumirse que todas las formas de expresión se encuentran protegidas, salvo que resulten violatorias de los límites constitucional y legalmente previstos.

Dentro de estos límites concurren los temporales que se mencionarán a continuación. La Ley General de Partidos Políticos, en su artículo 64 inciso 2 , brinda una definición de lo que se debe comprender como propaganda política en vía pública:

Se entiende por propaganda en vía pública toda propaganda que se contrate o difunda en espectaculares, buzones, cajas de luz, carteleras, marquesinas, muebles urbanos de publicidad con 0 sin movimiento, muros, panorámicos, para buses, puentes, vallas, vehículos o cualquier otro medio similar.

Ahora bien, según la LGIPE, propaganda electoral es el conjunto de escritos, publicaciones, imágenes, grabaciones, proyecciones y 


\section{DERECHO EIECTORAL}

expresiones que durante la campaña electoral producen y difunden los partidos políticos, los candidatos registrados y sus simpatizantes, con el propósito de presentar ante la ciudadanía las candidaturas registradas (art. 242.3). En concordancia con este inciso debe verse el mismo artículo, pero en su inciso 1 , donde se explica que por campaña electoral se entiende la serie de actividades llevadas a cabo por las agrupaciones políticas nacionales, las coaliciones y los candidatos registrados para la obtención del voto; y por otro lado, el concepto de los actos de campaña, según el inciso 2, que son las reuniones públicas, asambleas, marchas y en general aquellos en que los candidatos o voceros de los partidos se dirigen al electorado para promover sus candidaturas.

Resulta pertinente tomar en consideración que, según el artículo 251 del mismo cuerpo legal, la duración que tienen las campañas electorales federales, según los puestos de elección que vayan a estar en disputa será:

- Para los cargos de presidente de la República, senadores y diputados tiene una duración de 90 días, en el año en que corresponda celebrar los comicios (inciso 1 ).

- Para los puestos de diputados, cuando deba renovarse únicamente la cámara respectiva, el tiempo será de 60 días de duración (inciso 2).

En cuanto a las campañas estatales, el artículo 116. IV inciso j) de la Constitución señala las siguientes temporalidades:

- Para el cargo de gobernador la duración es de 60 a 90 días.

- Cuando se elijan diputados locales o ayuntamientos será de 30 a 60 días.

- La duración de las precampañas no excederá las dos terceras partes de las respectivas campañas.

Las campañas electorales de los partidos políticos inician a partir del día siguiente al de la sesión de registro de candidaturas para la elección de la que se trate, y finalizan tres días antes de las elecciones, ello en virtud del inciso 3 del artículo 251 de la LGIPE. 


\section{DERECHO ELECTORAL}

Una vez hechas tales anotaciones, incumbe observar las restricciones que pesan sobre la libre difusión de propaganda a lo largo del ordenamiento jurídico.

Previo a hacer mención de las prerrogativas y deberes de las agrupaciones políticas, la Ley de Partidos Políticos (artículo 26 inciso 1) aporta un derecho general: tener acceso a radio y televisión social en los términos que se estipulen tanto en la Constitución como en la LGIPE. Lo que conlleva la facilitación de medios para que las agrupaciones ejerzan la libre expresión en forma de propaganda electoral o mensajes generales. En relación con ello, la carta magna, en el numeral 41.III apartados b) y d) respectivamente, estipula que el tiempo que disponen los partidos políticos para trasmitir en los canales de radio y televisión social, durante la precampaña, es de un minuto cada 60 minutos. Por otro lado, en precampaña la propaganda electoral en las estaciones de radio y televisión deben, según tal norma, distribuirse en el periodo de programación comprendido entre las seis y las veinticuatro horas, y el tiempo restante se utilizará conforme se determine en la ley.

El numeral 251 de la LGIPE, en su inciso 4, contempla la limitación general: no se puede celebrar ni difundir reuniones, actos públicos de campaña, propaganda o proselitismo electorales el propio día de los comicios ni durante los tres días previos. Este periodo es conocido por el nombre de "veda electoral" o "tiempo de reflexión". (Animal Político, 2018, párr. 1)

En concordancia, en el artículo 210.1, también de la LGIPE establece que cuando se distribuya o coloque propaganda electoral deben respetarse los tiempos de ley, pero que, en todo caso, corresponderá retirarla tres días antes de la jornada electoral.

De lo relativo a las precampañas, también se estipula un límite de tiempo: los precandidatos a candidaturas para cargos de elección popular que participen en los procesos de selección interna de las agrupaciones políticas no pueden difundir propaganda electoral antes de iniciar la precampaña, según lo indica el artículo 226 inciso 3 de la LGIPE.

Con lo expuesto, se entiende que México contempla una veda electoral en la que no es permitido divulgar propaganda electoral tres días antes de los comicios, e incluso el propio día de la jornada electoral. Además, antes de comenzar las precampañas, quienes buscan postular su nombre en los 


\section{DERECHO ELECTORAL}

procesos de selección interna de las asambleas de los partidos políticos como precandidatos no pueden hacer propaganda electoral. Incumplir con ese mandato acarrea la negativa de registrarlos como precandidatos.

El Consejo General del Instituto Nacional Electoral puede ordenar la suspensión inmediata de cualquier propaganda política o electoral en radio o televisión que resulte violatoria de tales mandatos, como se señala en el numeral 163 de la LGIPE.

\subsection{Costa Rica}

El artículo 29 de la Constitución Política de Costa Rica, correlacionado con el $n .^{\circ} 28$, estipula la libertad que tienen los habitantes de la República de manifestar, sin previa censura, sus pensamientos. Así, como apunta Robles citado por Palacios (2018, p. 150), tanto la campaña electoral como la actividad de propaganda son manifestaciones concretas de esta libertad de expresión.

La normativa electoral ${ }^{4}$ del 2009 consignó en el artículo 94 inciso a) que propaganda electoral es la acción de los partidos políticos para preparar y difundir sus ideas, opiniones y programas de gobierno, y biografías de sus candidatos a puestos de elección popular, por los medios que sean considerados pertinentes. Esto durante el periodo de campaña, cuya duración es de cuatro meses, puesto que va desde la convocatoria a elecciones (que se realiza cuatro meses antes de la fecha de los comicios artículo 147 del CE) hasta el propio día de la votación (CE, art. 149).

La jurisprudencia electoral no solo define el concepto de propaganda política, entendiéndolo como cualquier actividad específicamente orientada a incidir en el comportamiento electoral de los ciudadanos; sino que, además, lo separa del de publicidad y considera a este último como el conjunto de medios que se emplean para divulgar sistemáticamente la acción propagandística electoral. Para el Tribunal Supremo de Elecciones, las prohibiciones cobijan tanto al autor de la propaganda como al responsable de su difusión publicitaria (resolución n. 0556-1-E-2001).

Al igual que el resto de naciones objeto de comparación, Costa Rica ha establecido límites a dicha libertad. En el caso de la propaganda electoral, las restricciones obedecen al respeto del orden e interés público (Rivera y

\footnotetext{
${ }^{4}$ De ahora en adelante CE, por las siglas del Código Electoral.
} 


\section{DERECHO ELECTORAL}

Abarca, 2010); sin embargo, y como lo estableció ya el Tribunal Supremo de Elecciones (TSE) en el considerando V del voto 220-E1-2018:

En una reiterada línea de decisión de este Pleno en cuanto a que, aun cuando el artículo 12 inciso j) del Código Electoral atribuye a este Tribunal la labor de "velar por el debido cumplimiento de la normativa referente a la propaganda electoral", ese encargo no se traduce en una habilitación para ejercer un control sobre el contenido de la propaganda de los partidos políticos en campaña electoral, al punto de suspenderla 0 modificarla, dado que esta únicamente es aplicable frente a las limitaciones y prohibiciones expresamente señaladas en la ley o en los instrumentos internacionales de protección de los derechos humanos vigentes en el ordenamiento costarricense.

En el mismo fallo, también en el considerando $V$, el TSE hace referencia a otras resoluciones, y menciona lo siguiente:

Desde esa consideración, y contrario sensu, el control que sí está habilitado para ejercer este Tribunal, en materia de propaganda político-electoral, se concentra en la fiscalización de los periodos de veda -de acuerdo con el artículo 136 del Código Electoral-, el cumplimiento de los requisitos legales y reglamentarios dispuestos para su reconocimiento con cargo a la contribución estatal (resolución n. ${ }^{\circ}$ 1792-E7-2008 de las 14:40 horas del 14 de mayo de 2008) y, por último, en la prevención de situaciones extraordinarias, como las prescritas en párrafo quinto del artículo 13 de la Convención Americana sobre Derechos Humanos (resoluciones n. ${ }^{\text {os }} 3426-E 7-2013$ y 3873-E8-2013).

Ahora bien, el Código Electoral costarricense atiende, en el numeral 136, una serie de prohibiciones en cuanto a la libertad de difundir proselitismo electoral, dentro de las que se encuentran la invocación de motivos religiosos, la colocación de propaganda en vía pública o en edificios públicos, y las vedas en razón del tiempo.

En cuanto a esta última categoría, y como apuntan Rivera y Abarca (2010, p. 23), el Código del 2009, a diferencia de la legislación anterior, vino a ser mucho más permisivo con las condiciones para la celebración de las 


\section{DERECHO EIECTORAL}

actividades político-electorales, así se propició una mayor participación de los partidos políticos en la campaña.

Los límites temporales que se han fijado aluden únicamente al periodo de tregua navideña, que inicia el 16 de diciembre y hasta el 01 de enero anteriores a la fecha de la contienda. Durante este lapso únicamente quienes aspiran a la presidencia de la República pueden divulgar tres mensajes navideños en los medios de prensa, radio y televisión debidamente inscritos ante el TSE ${ }^{5}$.

El segundo lapso de restricción atañe a la llamada veda publicitaria o veda electoral, que abarca el periodo comprendido entre los tres días anteriores inmediatos a los comicios electorales y el propio día de las elecciones, según el artículo 136 del CE.

Una tercera restricción aparece en el artículo 286 inciso c del CE, y tiene que ver con la difusión de propaganda cuando se trata de elecciones dentro de las agrupaciones políticas, dicho numeral prohíbe hacerlo los días jueves y viernes de la Semana Santa.

La violación de las disposiciones vinculadas con la divulgación de propaganda electoral constituye una falta electoral, prevista y sancionada en los artículos 286 y 289 CE, y acarrea multas pecuniarias para quien incumpla. Los partidos políticos responden solidariamente cuando la multa sea impuesta a uno de sus funcionarios en el ejercicio del cargo en el partido, como se fija en el numeral 299 del CE.

Rivera y Robles (2020, p. 14) exponen un rasgo interesante en el caso de Costa Rica, y es que el Código electoral del 2009 eliminó las antiguas restricciones de tiempo y espacio para la difusión de propaganda en prensa escrita, radio y televisión, pues lo dejó a criterio de los partidos políticos, pero ordenó igualdad de trato por parte de los medios de comunicación.

Si bien la legislación costarricense no hace manifestación expresa de las redes sociales y el internet como medios de difusión de propaganda política, al respecto el TSE, por medio del fallo n.0 0978-E8-2009, reconoció como elementos esenciales del concepto de propaganda

\footnotetext{
${ }^{5}$ La regulación específica de la veda navideña se encuentra en el párrafo cuarto del artículo 136 del Código Electoral, y su desarrollo en el Reglamento para la difusión de los mensajes navideños de los candidatos a la Presidencia de la República, decreto n. ${ }^{\circ}$ 27-2009.
} 


\section{DERECHO EIECTORAL}

electoral la intencionalidad y la herramienta utilizada, es decir, que lo que se divulgue tenga como fin captar el voto de los ciudadanos. Reza dicho voto lo siguiente:

Para poder calificar como propaganda electoral la información difundida en Internet [lo cual es aplicable, de igual manera, para el resto de informaciones independientemente del medio de difusión] se requiere la presencia concomitante de dos elementos: la intención y el mecanismo utilizado. En primer término, se debe identificar, en forma evidente o plausible, la intencionalidad de la información: influir en su opinión para que adopte determinado comportamiento electoral. Es decir, el contenido de la información debe denotar las características particulares del discurso propagandístico, a saber la intención de crear, transformar o confirmar opiniones a favor de ideas y creencias, a efecto de incidir en la ideología o creencia política de la persona. El otro elemento se refiere a la selección del medio idóneo para difundir esa información, de manera que logre el efecto deseado mediante un mecanismo de intromisión deliberada del mensaje en la esfera personal del receptor, de suerte tal que éste acceda a ese mensaje sin haberlo deseado con antelación.

A partir de la intencionalidad y la utilización de un medio idóneo para convencer a los ciudadanos de apoyar a determinado partido o candidato como requisitos de la propaganda electoral, es que se analiza si la veda aplica o no, y en qué forma, a las redes sociales y a lo difundido a través de internet en general.

Se concluye así que las agrupaciones políticas gozan de libertad para difundir propaganda en cualquier momento y por los medios de comunicación colectiva que estimen pertinentes. Solo no pueden hacerlo durante las épocas de veda (navideña y preelectoral). Sin embargo, aquella que se difunda fuera de la época o periodo de campaña (desde la convocatoria hasta el propio día de los comicios) no será objeto de reembolso con la contribución del Estado, de acuerdo con lo estipulado en el numeral 149 del CE en concordancia con el 136 del mismo cuerpo legal.

\subsection{Colombia}




\section{DERECHO ELECTORAL}

La Constitución Política de Colombia garantiza el derecho a la libertad de expresión en su artículo 20, el cual dispone la garantía de toda persona de expresar y difundir su pensamiento y opiniones, de informar y recibir información veraz e imparcial, y de fundar medios masivos de comunicación; todo sin censura previa.

En virtud de esta disposición, surge en la legislación colombiana la necesidad de limitar la manifestación política de la libertad de expresión, consistente en la divulgación de propaganda electoral. Con relación a ello, la Corte Constitucional, en el apartado de límites a la propaganda electoral del voto n. ${ }^{\circ}$ 959/06, manifestó que como derecho fundamental se encuentra también sujeto a restricciones. Así:

Cuando se trata de la selección de los contenidos que se van a difundir como propaganda electoral, no se debe atender únicamente el pretendido beneficio que un determinado mensaje le puede aportar al candidato promovido, sino que también se debe atender a los límites de la libertad de expresión que, aún cuando mínimos, salvaguardan importantes esferas relacionadas con los derechos de movimientos, partidos o personas y con valores fundantes del ordenamiento constitucional. Una campaña política tiene, entonces, la responsabilidad de seleccionar, de entre todos los testimonios recogidos, algunos para ser difundidos $y$, aunque en principio es dable pensar que le asistía la posibilidad de escoger con entera libertad los mensajes, no se puede pasar por alto que la difusión de la propaganda electoral puede comprometer libertades indispensables para un adecuado desarrollo del debate electoral, así como derechos de los partidos o movimientos políticos y aún de sus miembros individuales.

Ahora bien, la Ley Estatutaria n. ${ }^{\circ} 1475$ (2011), en su artículo 34, señala que la propaganda política es una de las actividades principales de la campaña y cumple la función de promover masivamente los proyectos electorales sometidos a consideración de los ciudadanos o una determinada forma de participación en la votación de que se trate. Un numeral después, el n. ${ }^{\circ} 35$, la define como toda forma de publicidad realizada con el fin de obtener el voto de los ciudadanos a favor de partidos 0 movimientos políticos, listas 0 candidatos a cargos 0 corporaciones públicas de elección popular, del voto en blanco, o de una opción en los mecanismos de participación ciudadana. 


\section{DERECHO ELECTORAL}

La misma norma estipula el primer límite temporal: en cuanto a los medios de comunicación social la difusión de propaganda solo tiene lugar dentro de los 60 días antes de la fecha de las elecciones correspondientes, y la que se realice utilizando el espacio público únicamente dentro de los tres meses previos a la fecha de los comicios respectivos.

Aunado a lo anterior, el artículo 3 del decreto n. ${ }^{\circ} 1924$ de 2019 consigna la prohibición de divulgar propaganda electoral por cualquier medio el propio día de las elecciones. Ya el Tribunal Constitucional (1994), por medio del fallo n. ${ }^{\circ}$ C-353/94, apartado C), había mencionado que esta limitación es acorde al derecho de la constitución cuando señaló lo siguiente:

En relación con el artículo 100. que prohibe [sic] la propaganda política y electoral en el día de las elecciones, estima que esa limitación es constitucional, pues no desconoce derecho alguno, en especial, los de información y libre expresión. Para sustentar su aserto cita la sentencia C-089 de 1994 de esta Corporación, en las que se consideró que el día de las elecciones puede limitarse el ejercicio de ciertos derechos con el fin de permitir al elector ejercer con toda libertad su derecho al voto.

La normativa electoral colombiana establece no solo límites temporales en lo vinculado a la divulgación de propaganda proselitista, sino que también otros de diversa índole como lo es el número de espacios permitidos en medios de comunicación social. Resulta interesante observar cómo en el artículo 35 de la ley n. $^{\circ} 1475$ (2011) se indica que los partidos, movimientos políticos, organizaciones sociales y los grupos significativos de ciudadanos que hayan inscrito candidatos a cargos de elección popular, y quienes promuevan el voto en blanco tienen derecho a espacios gratuitos en radio y televisión social, y fija toda una serie de reglas para su asignación. También, en el numeral 37 se estipula la existencia de un número máximo de vallas, cuñas y avisos que pueden tener en cada campaña los partidos, movimientos y grupos significativos de ciudadanos que hayan inscrito candidatos; correspondiéndole al Consejo Nacional Electoral el señalamiento de este.

Otro aspecto que llama poderosamente la atención es que las regulaciones son aplicables igualmente a los grupos que promueven el voto en blanco, este hecho incluso les otorga espacios en medios de comunicación, lo que los somete a todas las disposiciones propias de la propaganda electoral. 


\section{DERECHO EIECTORAL}

Recapitulando, entonces, la campaña electoral en Colombia posee una duración de 120 días en las elecciones presidenciales y 90 días para los comicios de otros cargos. La propaganda proselitista únicamente puede divulgarse dentro de los 60 días anteriores a la fecha propia, cuando se trate de medios de comunicación social, y de 90 días en espacios públicos. El día en el que se celebre la contienda electoral no puede divulgarse propaganda ni comunicados ni manifestaciones con fines políticoelectorales, en radio, prensa y televisión, así como la propaganda móvil, estática o sonora; tampoco cabe colocar nuevos elementos para difundir propaganda electoral, ni realizarlo a través de vehículos terrestres, naves o aeronaves.

\subsection{URUGUAY}

El último país que se analizará es Uruguay, en donde la libertad de expresión encuentra sustento constitucional, como en los demás países analizados. Reza la Constitución de la República Oriental de Uruguay en su artículo 29:

Es enteramente libre en toda materia la comunicación de pensamientos por palabras, escritos privados o publicados en la prensa, o por cualquier otra forma de divulgación, sin necesidad de previa censura; quedando responsable el autor $y$, en su caso, el impresor o emisor, con arreglo a la ley por los abusos que cometieren.

A diferencia de las demás naciones analizadas, Uruguay cuenta con una ley especial que regula la propaganda electoral, a saber la ley $n .^{\circ} 16.019$ sobre la publicidad política para elecciones, plebiscitos y referéndum, con una peculiaridad que la distingue también de los otros casos, y es justamente que el primer artículo de tres estipula una restricción a la difusión de propaganda electoral: todo acto de propaganda proselitista en vía pública, en locales abiertos o en medios de comunicación (ya sea radio, prensa o televisión) debe finalizar 48 horas antes del propio día de los comicios.

La segunda limitación temporal encontrada (que requiere aunarse a la veda de las 48 horas) responde a lo indicado en el artículo único de la Ley 


\section{DERECHO EIECTORAL}

n. ${ }^{\circ} 17.818^{6}$, de los plazos para la propaganda electoral en los medios de información masiva. En él se contempla que los plazos con los que cuentan las agrupaciones políticas corresponden, según el tipo de elección de la que se trate, de la siguiente manera:

30 días para las elecciones internas de los partidos políticos.

30 días para los comicios nacionales.

15 días cuando se trate de una segunda ronda electoral.

30 días para elecciones departamentales.

Ahora bien, la Ley $n .^{\circ} 17.045$ especifica qué es lo que se entiende por publicidad electoral ${ }^{7}$. El artículo 2 la define como la serie de actos que se realizan a través de piezas elaboradas, especializadamente, con criterios profesionales y comerciales; y a su vez, excluye de este concepto la divulgación de información sobre actos políticos y actividades habituales del funcionamiento de los partidos, y la realización de entrevistas periodísticas.

Los demás artículos de la ley citada establecen espacios gratuitos en radio y televisión con los que cuentan los candidatos a cargos de elección popular, y los requisitos para poder acceder a ellos, por ejemplo pertenecer a partidos con representación parlamentaria, y/o haber alcanzado un porcentaje igual o mayor al $3 \%$ de los habilitados para votar, en las elecciones internas; además de estipular que, en cuanto a las encuestas electorales y consultas, podrán ser difundidas una vez cerrado el horario oficial de votación.

Quien ostenta la competencia para controlar lo correspondiente es la Corte Electoral, órgano con rango constitucional, encargado de conocer todo lo relacionado con los actos y procedimientos electorales; ello según los numerales 77 y 132 de la Constitución Política, en concordancia con el artículo 7 de la Ley de Elecciones, n. 0 7.812, al instituir también la función de controlar el proceso electoral y sus vicisitudes. Se observa en la legislación electoral uruguaya la invisibilización en cuanto a regulación

\footnotetext{
${ }^{6}$ Responde a una reforma al artículo primero de la Ley n. ${ }^{\circ} 17.045$. Todo lo demás, salvo el numeral 1 , permanece incólume.

${ }^{7}$ La Ley $n .^{\circ} 17.045$ señalada utiliza el nombre de publicidad electoral y no de propaganda.
} 


\section{DERECHO ELECTORAL}

que se les hace a los medios de información alternativos como las redes sociales.

En síntesis, el derecho electoral en Uruguay contempla un periodo de veda de 48 horas previos al día en el que se celebran los comicios. Durante este periodo los partidos deben abstenerse de divulgar publicidad electoral, dejando por fuera todo lo que el artículo 2 de la ley $n$. ${ }^{\circ} 17.045$ no contempla como propaganda electoral.

\section{A MODO DE CONCLUSIÓN}

La libertad de expresión, vista como la capacidad que tienen los seres humanos de externar sus opiniones, ideas, creencias y pensamientos, por cualquiera que sea la forma (oral, escrita, no verbal, artística, etc.) y sin previa censura, ha sido admitida como una de las garantías más importantes de las personas, en el entendido de que se establece dentro de la mayoría de los instrumentos internacionales, como la Declaración Universal de los Derechos Humanos, Declaración Universal de los Derechos del Hombre, el Pacto Internacional de Derechos Civiles y Políticos, la Convención Americana de Derechos Humanos, Convención Europea de Derechos Humanos y demás cartas.

No solo ha sido adoptado por los países que ratifican estos tratados, sino que también se ha fijado como un límite al poder del Estado en el tanto se erige como un derecho fundamental previsto en la mayoría de las constituciones. En cada uno de los cuatro ordenamientos analizados la libre expresión se encuentra catalogada como una de las libertades individuales de los ciudadanos. Empero, sabemos que esta garantía, además de su dimensión individual, es un vehículo para concretar otras libertades de las personas en su desenvolvimiento en sociedad, lo que le otorga a este concepto una dimensión social también.

Partiendo de que ningún derecho fundamental es absoluto, la libertad de expresión puede verse limitada por razones sociales, como el interés, orden, la salud y la seguridad públicas (entre otros). Dentro de estos parámetros se encuentran los límites a la propaganda electoral, conocida también como propaganda proselitista, propaganda política, etcétera.

Muchos de los países latinoamericanos incluyen en su legislación límites temporales como la veda electoral, o -periodo de reflexión-, en el que se 


\section{DERECHO EIECTORAL}

prohíbe la difusión de propaganda política horas o días antes de la celebración de los actos comiciales.

De los casos expuestos, tres contemplan un periodo de reflexión previo al día de las elecciones. Tanto México como Costa Rica prohíben (aunada a otras restricciones) la difusión de propaganda tres días antes del día de la votación. Para Uruguay, la veda se establece no en tres, sino dos días antes de las elecciones. A diferencia de estos tres países, Colombia no contempla una veda previa, sino que la prohibición es únicamente para el propio día de los comicios. Costa Rica contempla este periodo de reflexión $y$, además, instauró una tregua navideña que va del 16 de diciembre al 01 de enero previos a las elecciones.

Como se indicó, los límites no se reducen a la temporalidad. Si bien el objeto de estudio fue el temporal, se vislumbró cómo incluso se merma la propaganda proselitista de otras formas. Un ejemplo es la prohibición expresa del Código Electoral costarricense de difundir propaganda electoral invocando motivos religiosos. Otras tienen que ver con la cantidad o los espacios asignados en medios de comunicación oficiales, o el impedimento de colocarla en determinados espacios públicos, y demás.

De los cuatros países estudiados, se observa que quien deja más abierto el tema de cómo se sanciona la trasgresión a estas prohibiciones es Uruguay; mientras que la legislación en Costa Rica y México es mucho más detallada.

Para finalizar, no debe perderse de vista que, si bien los derechos no son absolutos, en el caso de la libertad de expresión (en su arista de propaganda política) los límites deben atender efectivamente a asuntos de interés y orden públicos, sin teñirse de censura y de ningún modo antojadizos; pues violentar la libertad comunicación del pensamiento conlleva inevitablemente perder ciudadanos conscientes e informados sobre los comicios y sobre el quehacer del gobierno en general.

\section{Referencias bibliográficas}

Fiss, O. (2005). Una libertad tanto personal como política. Revista jurídica de la Universidad de Palermo, (1), 39-54.

Lozano, J. (2000). Límites y controles a la libertad de expresión. Serie: Estudios 


\section{DERECHO EIECTORAL}

Básicos de Derechos Humanos, (tomo X), 240-261.

Orozco, J. (2019). Justicia electoral comparada de América Latina. Instituto de Investigaciones Jurídicas serie Doctrina Jurídica, (853), 153-172.

Marciani, B. (2005). La posición preferente del derecho a la libertad de expresión: un análisis crítico de sus fundamentos. Pensamiento Constitucional, (11), 351-378.

Morán, E. y Valencia, M. (2016). La libertad de expresión en procesos electorales. El caso de las redes sociales. Ciencia Jurídica, (10), 155-169.

Muñoz, H. A. (1988). Propaganda político-electoral. En Diccionario electoral, pp. 546-555. San José: Instituto Interamericano de Derechos Humanos. Editorial Ediarte.

Palacios, L. G. (2018). Libertad de expresión y propaganda electoral a partir de la lectura moral de la constitución propuesta por Ronald Dworkin. Revista de Derecho Electoral, (28), 141-160.

Peralta, R. (2012). Libertad ideológica y libertad de expresión como garantías institucionales. Anuario iberoamericano de justicia constitucional, (16), 251283.

Rivera, J. L., Abarca, G. (2010). La propaganda electoral en el Código Electoral. Revista de Derecho Electoral, (9), 1-47.

Rivera, J. L. Robles, A. J. (2020). La regulación de la propaganda electoral en Costa Rica. Serie Para Entender, (8), 4-14.

Tinant, E. (2011). El principio de dignidad humana. Boletín del Consejo Académico de Ética en Medicina, (8), 1-4.

Tórtora, H. (2010). Las limitaciones a los derechos fundamentales. Estudios constitucionales, (8), 167-200.

\section{Sitios web}

Animal Político. (2018). Veda electoral: esto es lo que los candidatos tienen prohibido hacer a partir de este jueves. Recuperado de: https://www.animalpolitico.com/2018/06/veda-electoral-esto-es-lo-que-loscandidatos-tienen-prohibido-hacer-a-partir-de-este-jueves/

Capital Digital. (2017). ¿Qué es una precampaña electoral? Recuperado de: https://www.capitalmexico.com.mx/nacional/precampana-electoralprecandidato-presidencia-aspirantes-partidos-politicos-tiempos/ 


\section{DERECHO EIECTORAL}

Corona, L. (s. f). Propaganda electoral y propaganda política. Recuperado de: http://derecho.posgrado.unam.mx/congresos/congreibero/ponencias/LuisAn tonioNakamura.pdf

Comisión Interamericana de Derechos Humanos. (2000). Declaración de Principios sobre Libertad de Expresión. Recuperado de: https://biblioteca.iidh-jurisprudencia.ac.cr/index.php/documentos-enespanol/legislacion-internacional/sistema-interamericano/instrumentosdeclarativos/2121-declaracion-de-principios-sobre-libertad-de-expresion$\underline{2000 / \text { file }}$

Instituto Interamericano de Derechos Humanos. (2017). Diccionario Electoral, tomo II. Recuperado de: https://www.iidh.ed.cr/capel/media/1441/diccionario-electoral tomo-ii.pdf

Real Academia Española. (2001). Diccionario de la lengua española (22.a ed.). Recuperado de http://www.rae.es/rae/honor

Relatoría Especial para la Libertad de Expresión. (2019). Guía para garantizar la libertad de expresión frente a la desinformación deliberada en contextos electorales.

Recuperado

de: http://www.oas.org/es/cidh/expresion/publicaciones/Guia Desinformacion VF.pdf

Reporteros Sin Fronteras. (2021). Clasificación Mundial de la Libertad de Prensa 2021. Recuperado de: https://rsf.org/es/metodologia-detallada

Uruguay Presidencia. (2018). Uruguay es el país con la democracia plena más avanzada de América Latina y el Caribe. Recuperado de: https://presidencia.gub.uy/comunicacion/comunicacionnoticias/indicedemocracia-2018

\section{Legislación}

Colombia (1991). Constitución Política de Colombia. Publicada en la Gaceta Constitucional n. ${ }^{\circ} .116$ de 20 de julio.

Colombia (2019). Decreto n. ${ }^{\circ} 1924$. Diario Oficial, veintitrés de octubre.

Colombia (2011). Ley Estatutaria n. ${ }^{1475}$. Diario Oficial, catorce de julio.

Costa Rica (2009). Código Electoral, Ley n. 8765. Diario Oficial La Gaceta, del dos de setiembre de 2009.

Costa Rica (1949). Constitución Política de la República de Costa Rica del 7 de noviembre. 


\section{DERECHOELECTORAL}

Francia. Asamblea Nacional Constituyente (1789). Declaración Universal de Derechos del Hombre y del Ciudadano.

México (1917). Constitución Política de los Estados Unidos Mexicanos.

México (2014). Ley General de Instituciones y Procedimientos Electorales. Diario Oficial de la Federación, veintitrés de mayo.

México (2014). Ley General de Partidos Políticos. Diario Oficial de la Federación, veintitrés de mayo.

Organización de las Naciones Unidas (1966). Pacto Internacional de Derechos Civiles y Políticos del 16 de diciembre.

Organización de las Naciones Unidas (1948). Declaración Universal de Derechos Humanos.

Concejo de Europa (1953). Convenio Europeo de Derechos Humanos.

Organización de los Estados Americanos (1969). Convención Americana de Derechos Humanos.

Uruguay (1925). Ley n. ${ }^{0}$ 7.812. Registro Nacional de Leyes y Decretos, del 16 de enero.

Uruguay (1967). Constitución de la República Oriental de Uruguay del 2 de febrero.

Uruguay (1989). Ley n. ${ }^{\circ} 16.019$. Registro Nacional de Leyes y Decretos, cinco de abril.

Uruguay (2004). Ley $n .^{\circ} 17.018$. Registro Nacional de Leyes y Decretos, catorce de setiembre.

Uruguay (1998). Ley n. ${ }^{\circ}$ 17.045. Registro Nacional de Leyes y Decretos, veintiuno.

\section{Jurisprudencia}

Consejo General del Instituto Nacional Electoral de México. (2017). Resolución n. ${ }^{\circ}$ INE/CG338/2017, del nueve de agosto.

Corte Constitucional de Colombia (1994). Resolución n. C-353/94 del diez de agosto. 


\section{DERECHO ELECTORAL}

Corte Constitucional de Colombia (2006). Resolución n. T-959/06 del veinte de noviembre.

Tribunal Electoral del Poder Judicial de la Federación (2010). Resolución n. SUPRAP-119/2020 del veinticinco de agosto.

Tribunal Supremo de Elecciones de Costa Rica (2001). Resolución n. 0556-E12001 de las dieciséis horas del veintiuno de febrero.

Tribunal Supremo de Elecciones de Costa Rica (2009). Resolución n. 0978-E82009 de las once y cuarenta y cinco horas del diecinueve de febrero.

Tribunal Supremo de Elecciones de Costa Rica (2018). Resolución n. ${ }^{\circ}$ 0220-E12018 de las diez horas del dieciséis de enero. 